\title{
The Impact of Physical Work Demands on Need for Recovery, Employment Status, Retirement Intentions, and Ability to Extend Working Careers: A Longitudinal Study Among Older Workers
}

Citation for published version (APA):

Gommans, F., Jansen, N., Mackey, M. G., Stynen, D., de Grip, A., \& Kant, I. (2016). The Impact of Physical Work Demands on Need for Recovery, Employment Status, Retirement Intentions, and Ability to Extend Working Careers: A Longitudinal Study Among Older Workers. Journal of Occupational and Environmental Medicine, 58(4), E140-E151. https://doi.org/10.1097/JOM.0000000000000687

Document status and date:

Published: 01/04/2016

DOI:

10.1097/JOM.0000000000000687

Document Version:

Publisher's PDF, also known as Version of record

Document license:

Taverne

Please check the document version of this publication:

- A submitted manuscript is the version of the article upon submission and before peer-review. There can be important differences between the submitted version and the official published version of record. People interested in the research are advised to contact the author for the final version of the publication, or visit the DOI to the publisher's website.

- The final author version and the galley proof are versions of the publication after peer review.

- The final published version features the final layout of the paper including the volume, issue and page numbers.

Link to publication

\footnotetext{
General rights rights.

- You may freely distribute the URL identifying the publication in the public portal. please follow below link for the End User Agreement:

www.umlib.nl/taverne-license

Take down policy

If you believe that this document breaches copyright please contact us at:

repository@maastrichtuniversity.nl

providing details and we will investigate your claim.
}

Copyright and moral rights for the publications made accessible in the public portal are retained by the authors and/or other copyright owners and it is a condition of accessing publications that users recognise and abide by the legal requirements associated with these

- Users may download and print one copy of any publication from the public portal for the purpose of private study or research.

- You may not further distribute the material or use it for any profit-making activity or commercial gain

If the publication is distributed under the terms of Article 25fa of the Dutch Copyright Act, indicated by the "Taverne" license above,

Download date: 26 Apr. 2023 


\title{
The Impact of Physical Work Demands on Need for Recovery, Employment Status, Retirement Intentions, and Ability to Extend Working Careers
}

\author{
A Longitudinal Study Among Older Workers
}

\author{
Fleur G. Gommans, MSc, Nicole W.H. Jansen, PhD, Martin G. Mackey, PhD, Dave Stynen, PhD, \\ Andries de Grip, PhD, and IJmert Kant, PhD
}

\begin{abstract}
Objective: Prospectively investigating whether different approaches of physical work demands are associated with need for recovery (NFR), employment status, retirement intentions, and ability to prolong working life among older employees from the industry and health care sector. Methods: A subsample from the Maastricht Cohort Study was studied $(n=1126)$. Poisson, Cox, and logistic regression analyses were performed to investigate outcomes. Results: Perceiving physical work demands as strenuous was associated with higher NFR. Continuous physical strain was associated with being out of employment 4 years later. Employees with the highest amount of physical work demands perceived they were less able to prolong working life, although no significant associations between physical work demands and retirement intentions were found. Conclusions: Overall, physical work demands were associated with adverse outcomes, with divergent insights for the different approaches of physical work demands.
\end{abstract}

A $\mathrm{s}$ the population is aging in many industrialized countries, older employees may have to postpone retirement in order to sustain current pension systems. Several measures (eg, abolishment of early retirement schemes, postponing the mandatory retirement age) have been undertaken to extend working careers, which have resulted in a recent increase in the average retirement age. In the Netherlands, the average age at which employees retire has increased from 61.0 years in 2006 to 64.1 years in $2014,{ }^{1}$ and in recent years, more employees have prolonged their working life until reaching their mandatory retirement, which will be gradually extended to the age of 67. ${ }^{2}$ However, differences in workers' intentions and ability to prolong their working life until their mandatory retirement age, which can be problematic with respect to labor participation, can be observed when investigating different economic sectors.

Willingness and ability to prolong working life should be considered two distinctive concepts, as factors associated with these two concepts differ. For example, a study ${ }^{3}$ found that lower job autonomy was associated with a lower ability, but not with a reduced willingness to prolong working life. Both the lowest intention and the lowest ability to work until reaching the mandatory retirement age were observed in the industry and the health care sectors. ${ }^{4}$ The intention to prolong working life beyond the age of 65 was also low

From the Department of Epidemiology, CAPHRI School for Public Health and Primary Care, Faculty of Health, Medicine and Life Sciences, Maastricht University, Maastricht, The Netherlands (Gommans, Jansen, Stynen, Kant); Discipline of Physiotherapy, Faculty of Health Science, The University of Sydney, Sydney, NSW, Australia (Mackey); and Research Centre for Education and the Labour Market (ROA), Maastricht University, Maastricht, The Netherlands (de Grip).

The authors report no conflicts of interest.

Address correspondence to: Fleur G. Gommans, MSc, Department of Epidemiology, School for Public Health and Primary Care (CAPHRI), Maastricht University, P.O. Box 616, 6200 MD, Maastricht, The Netherlands (Fleur.Gommans@maastrichtuniversity.nl).

Copyright (C) 2016 American College of Occupational and Environmental Medicine

DOI: $10.1097 / J O M .0000000000000687$ in these sectors, as compared to other economic sectors. ${ }^{4}$ A possible explanation for this might be found in the performance of physically demanding work, common in both of these sectors. ${ }^{5}$

Different studies ${ }^{6,7}$ have demonstrated associations between physically demanding work and early retirement and absence of sickness. Also, it has been acknowledged that among economic sectors characterized by physical work demands, special incentives will be required to extend opportunities for meaningful employment. ${ }^{8}$ However, direct associations between physical work demands and both the intention and ability to prolong working life have not often been investigated. ${ }^{9}$ Moreover, physical work demands might be associated with intentions, and ability, to prolong work life through an indirect pathway of need for recovery (NFR), a concept reflecting the short-term effects of a working day. Several studies ${ }^{10,11}$ demonstrated associations between physical work demands and high levels of NFR. Typically, workers use and deplete mental and physical resources ${ }^{12}$ during working days, which results in the need to recuperate from work-induced effects. Employees with elevated NFR are characterized by feelings of overload, social withdrawal, and reduced performance and are more likely to reduce working hours and change jobs within an organization. ${ }^{13}$ Moreover, NFR is associated with sickness absence ${ }^{14}$ and occupational disability, ${ }^{15}$ which in turn might be associated with the chance to lose employment as well as the intentions and ability of employees to prolong working life. Also, NFR was found to be associated with early retirement. ${ }^{3}$

Besides physical work demands, other factors such as personal characteristics (eg, age, gender) and employees' health might also be associated with NFR and retirement intentions. For example, in earlier studies ${ }^{16,17}$ NFR was investigated among different subgroups of older workers with the highest levels of NFR observed among those aged 50 to 54 years and 46 to 55 years, whereas both studies found a decrease in NFR after the age of 55 years. Also, gender was found to be associated with NFR. ${ }^{18}$ Furthermore, greater sports and leisure-time physical activity are often considered to be protective factors for NFR. ${ }^{19}$ Also, a perceived poor health is associated with early retirement intentions. ${ }^{20}$

When investigating the impact of physical work demands on these outcomes, the presence of a healthy worker effect should also be considered, as selection effects are likely to occur among employees involved in physically demanding jobs. ${ }^{21}$ Different manifestations of the healthy worker effect are possible ${ }^{22}$ : a primary selection effect, in which employees decide to not engage in a physically demanding job, and a secondary selection effect, which arises when employees with physical work demands accumulate less exposure to physical work demands over time; for example, if after experiencing that their present job conflicts with their feelings or health, they switch to a job with lower exposure levels such as sedentary work. A tertiary selection effect may occur when employees with physical work demands selectively drop-out from the study population, while is it hypothesized that this dropout occurs due to a 
decrease in physical work capacity. Possibly, these types of selection effects will bias the true results of a study, as only a selected group of employees capable of performing physically demanding work will remain employed in such jobs.

Another complicating factor when investigating the effects of physical work demands concerns the complexity and ambiguity of the concept. The concept of physical work demands includes multiple approaches, and various methods exist to objectively or subjectively assess the amount of physical work tasks performed by employees. ${ }^{23}$ Although many studies focus on one particular aspect of physical work demands, the present study examines different approaches of physical work demands. The rationale for this aim is that it is valuable to consider both the amount of physical work demands and whether physical work demands are perceived as strenuous, as possibly, having a large amount of physical work demands in a job might not necessarily imply a highly perceived physical intensity of work demands. Furthermore, different patterns of cumulative exposure to physical work demands during the life course should be taken into account, as for example, cumulative physical work demands are found to be associated with health complaints. $^{24}$ Therefore, much exposure to high physical work demands throughout the work career might be differently associated with outcomes, as compared to little or infrequent exposure.

The aim of this study is to prospectively investigate the impact of different approaches of physical work demands (comprising the amount, the perception and the patterns of cumulative exposure) on older employees' NFR; the risk of being out of employment; and the intentions and ability of employees to prolong working life among those who are employed in the industry and health care sectors, while considering possible confounders. There are several reasons why this sector-specific approach will be valuable. First, physical work demands are expected to be highly prevalent within both sectors, although the work environment and conditions differ across these two sectors. This actuality allows for the investigation of physical work demands in different work environments. Second, retirement schemes can be sector-specific and might influence retirement decisions of employees. By investigating two economic sectors separately, homogeneous study populations in terms of retirement schemes will be investigated. To determine whether the results of this study are a possible underestimation of true findings, this study additionally aims to illustrate a tertiary healthy worker effect.

\section{METHODS}

\section{Study Population}

Data from the Maastricht Cohort Study (MCS) was used. This ongoing prospective cohort was set up in May 1998 and included at baseline measurement 12,140 participants from 45 different companies (each with $>100$ employees), who were employed in different occupations and sectors. During follow-up, data were collected by means of self-administrated questionnaires at regular time intervals. The design of the MCS is described elsewhere in detail. ${ }^{25,26}$ In the present study, two economic sectors were investigated: industry and health care.

For the present study, October $2008(n=6073)$ wave was considered the starting point for the current analyses. To construct the study population, all respondents aged 45 years and older who were occupied in the industry or health care sector and who indicated to be employed at follow-up wave October 2008 were included. Employees involved in multiple jobs and pregnant women were excluded. Also, employees who were retired at wave October 2012 were excluded, as the measurement of (other) outcomes of these employees may be biased due to their situation. This resulted in a total study population of $n=1126$, of which $n=816$ were employed in the industry and $n=310$ in the health care sector.

\section{Physical Work Demands}

Different approaches were used to assess physical work demands. The Baecke index ${ }^{27}$ was used to rate the amount of physical work demands at waves October 2008 and October 2012. The Baecke index assesses habitual patterns of physical activity performed by an individual and comprises three domains: work, sports and exercise, and leisure-time physical activity. The Baecke work index quantifies the amount of physical activity performed in the occupational domain and comprises eight items. In line with the instruction manual of the Baecke questionnaire, first, information on the type of occupation and tasks performed within this occupation was gathered, which, with use of the Ainsworth physical activity compendium, ${ }^{28}$ converts employees' occupations into three categories of energy expenditure: light, moderate, or vigorous with corresponding scores 1,3 , and 5, respectively. Next, seven items on occupational physical activities were included, all measured on five-point scales. An example of an item is "At work I lift heavy loads' with response options ranging from "never" to "always". The original sum score of all eight occupational items was divided by 8 , resulting in a Baecke work index with a semicontinuous range from 1 to 5 . This was calculated for all employees who did not have any missing value on these eight items $(n=85$ excluded). To investigate subgroups with different amounts of occupational physical activity, this range was further divided into sample-specific quartiles, which is in line with earlier studies. ${ }^{29,30}$ Here, quartile 1 (reference group) implies the lowest amount and quartile 4 the highest amount of physical work demands. In this study, the following cut-off scores were used to define the Baecke work index quartiles: 2.000 or less (quartile 1), more than 2.000 to 2.375 or less (quartile 2), more than 2.375 to 3.125 or less (quartile 3 ), and more than 3.125 (quartile 4).

The perception of physical work demands as strenuous was measured by means of one dichotomous item ${ }^{31}$ from the Dutch questionnaire on Work and Health: "Do you consider your job to be strenuous? (yes/no)," in which employees who did not consider their job to be strenuous were considered the reference group.

Whereas both the amount and perception of physical work demands provide insight into the physical work demands at study baseline, additionally, possible cumulative patterns that might have originated before study baseline were investigated to examine longterm effects of physical work demands. The latter item was also used to construct different patterns of cumulative exposure to physical work demands. Although measurement October 2008 was the starting point to construct the cumulative patterns, information from three preceding waves on the perception of physical work demands as strenuous was also included. First, the perception of physical work demands as strenuous was assessed at wave October 2008 in the study population. Next, the perception of physical work demands as strenuous at waves May 1998, May 1999, and May 2000 was examined (the perception of physical work demands as strenuous was examined only at those earlier waves of the cohort) to construct the cumulative patterns. On the basis of these four measurements, four subgroups with different cumulative patterns were defined: a "nonstrainer" group, comprising employees who did not perceive their job as strenuous at any of these four measurements ( $n=688$, reference group). A "delayed strainer" group, comprising employees who perceived their job as strenuous only at wave 2008 , but as not strenuous in all earlier measurements $(n=84)$, an "early strainer" group, who did not perceive their job as strenuous in 2008, but who did perceive their job as strenuous at all earlier measurements $(n=148)$, and a "continuous strainer" group, comprising employees who perceived their job as strenuous at all four measurements $(n=93)$.

\section{Need for Recovery}

NFR was measured at waves October 2008 and October 2012 and was assessed with a subscale from the Dutch Questionnaire on 
the Experience and Evaluation of Work (VBBA). ${ }^{11}$ This subscale contains 11 dichotomous items (yes/no), representing the short-term effects of a working day, resulting in a scoring range of $0-11$. An example of an item is "After a working day, I am often too tired to start other activities." An earlier defined cut-off point of $6^{32}$ was used to define NFR caseness: employees scoring below the cut-off point are considered to have a low-medium level of NFR and employees scoring above the cut-off point are considered cases with an elevated level of NFR. The subscale was also recoded into a continuous scale with a range of $0-100$ : a higher score indicating a higher NFR.

\section{Employment Status}

At wave October 2012, the respondents' employment status was determined. Respondents first indicated whether they were currently employed (yes/no). Those who indicated that they were not employed could further indicate that they were actively in search for employment, (partly) disabled for work, housewife/houseman, performing voluntary work, and/or receiving income from unemployment benefits or social assistance benefits. Employees who indicated that they were currently unemployed, and/or indicated one or more of the above-mentioned situations for current unemployment, were classified as being no longer employed during follow-up.

\section{Retirement Intentions and Ability to Prolong Working Life}

Several items on retirement intentions, and ability to prolong working life until and beyond the mandatory retirement age, were assessed at wave October 2012. To measure retirement intentions, two items based on an earlier study ${ }^{33}$ were investigated. The first item measured intentions to prolong working life until reaching the mandatory retirement age: "It is my intention to keep working until I reach the mandatory retirement age." The second item measured intentions to prolong working life beyond the mandatory retirement age: "It is my intention to keep working beyond the mandatory retirement age." Both items were scored on a five-point Likert scale, with response options ranging from "strongly disagree" to "strongly agree." These response categories were recoded into two categories, resulting in a " (strongly) agree" category and a "neutral to (strongly) disagree" category, which henceforth will be referred to as "agree" and "disagree" categories, respectively.

Two items measured employees' ability to prolong their working life. The first item was based on an earlier study ${ }^{34}$ and assessed whether employees think they are physically able to perform their current job until reaching the mandatory retirement age. The item was scored on a five-point Likert scale, with response options ranging from "strongly agree" to "strongly disagree." Here, the five response categories were recoded into similar "agree" and "disagree" categories as the response options of the retirement intentions. The second item ${ }^{35}$ assessed whether less physical demands in the job would contribute to the prolongation of working life beyond the mandatory retirement age. The item was scored on a four-point scale, with response options "to a large extent," "to some extent," "to a small extent," and "not at all." The response options were again dichotomized by recoding the first three response options into "at least some extent" and "not at all" into "no extent."

\section{Confounding Factors}

Potential confounders were all measured at wave October 2008, except for respondents' educational level and the confounders adjusted for in the cross-sectional analysis comprising October 2012 data. Potential confounders in the personal and health domain comprised age, gender, living alone (yes/no), and self-perceived health. Self-perceived health was measured with one item from the
SF-36 Health Survey ${ }^{36}$ : "How would you rate your health in general?" Five response options were "excellent" "very good," "good," "moderate," or "bad" and were dichotomized in line with earlier studies ${ }^{37,38}$ by grouping "excellent," "very good," and "good" into "good health" and "moderate" and "bad" into "poor health." Highest level of educational was assessed at May 1998. It was classified at three levels: low (primary school, lower vocational education), medium (lower secondary school, intermediate vocational school, upper secondary school), or high (higher vocational school, university).

Sports and exercise, and leisure-time physical activity were measured using the corresponding scales of the Baecke index. The Baecke sports and exercise index comprised seven items, first assessing whether employees participate in sports. For those participating in sports, the most frequently performed sport was asked. By means of the Ainsworth physical activity compendium, ${ }^{28}$ the energy expenditure of this sport was classified as light, moderate, or vigorous. Next, the number of hours per week and months per year spent on this sport were assessed. For a second sport in which employees were possibly engaged, again the type of sport, time, and proportion spent on this sport were assessed. In accordance with the formula proposed by Baecke, the total Baecke sports and exercise index was calculated, resulting in a semicontinuous range of 1 to 5 . Seven items assessed leisure-time physical activity. All items were measured on a five-point scale and included, for example, items on the prevalence of watching television and cycling during leisure time. In accordance with the formula proposed by Baecke, the total Baecke leisure-time index with a semicontinuous range of 1-5 was calculated.

Potential confounders from the work environment included psychological job demands, which are measured by a scale from the validated Dutch version ${ }^{39}$ of the Job Content Questionnaire (JCQ) ${ }^{40}$ To measure decision latitude, two subscales from the JCQ were combined: skill discretion and decision authority. Also, two scales from the JCQ were used to measure coworker social support and supervisor social support, each. Both scales comprise four items. All scales from the JCQ had four response options, ranging from "strongly disagree" to "strongly agree." To measure emotional demands in the job, one dichotomous item (yes/no) from the Dutch questionnaire on Work and Health was used. The number of working hours per week were measured by one item including response options more than 40,36 to 40,26 to 35,16 to 25 , or less than $16 \mathrm{~h}$ per week. One item measured the performance of shift work (yes/no). Also, living alone, gender, self-perceived health, and educational level were included as confounders in the cross-sectional analysis comprising October 2012 data. Identical items as mentioned earlier were used, although here the confounders included were assessed only at wave October 2012.

\section{Statistical Analysis}

To describe the study population at baseline (October 2008), $\chi^{2}$-tests were conducted to test for differences in the prevalence of personal, health and work characteristics, and NFR caseness between the two categories of perceiving physical work demands as strenuous.

$T$-tests were conducted to compare the continuous mean scores of the Baecke work, sports and exercise, and leisure-time indexes. To take into account the positively skewed distribution of NFR, Poisson regression analysis (with scaled deviance) is considered the appropriate method to compare mean NFR scores between the two categories. Also, $\chi^{2}$-tests were conducted to test for differences in NFR caseness between the Baecke work index quartiles.

To investigate the longitudinal association between physical work demands at wave October 2008 and NFR at wave October 2012, Poisson regression analyses were conducted. In this study, all 
employees who were a case of elevated NFR at wave October 2008 were excluded $(n=283)$ in the longitudinal analyses in which NFR was the outcome measure. The reason for this exclusion was that this study aimed to investigate the development of elevated NFR and not the natural course of NFR among those already dealing with an elevated NFR. The continuous NFR scores of both the two categories of perceiving physical work demands as strenuous or not and the Baecke work index quartiles were investigated. Four models were investigated: a model adjusting for age (model 1), a model additionally adjusting for gender, living alone, educational level, self-perceived health, and number of working hours per week (model 2), a model additionally adjusting for the Baecke sport and exercise and leisure-time index scores (model 3), and a model additionally adjusting for psychological job demands, decision latitude, shift work, emotionally demanding work, social support from coworkers, and social support from supervisor (model 4). Unstandardized regression coefficients $(\beta)$ for the risk of a higher NFR and standard errors (SE) were reported.

Although this study aimed to stratify results by economic sector, in some analyses sample size did not allow stratification; in that case, an unstratified model including both sectors was presented. To longitudinally investigate the association between different patterns of cumulative exposure to physical work demands and NFR at wave October 2012, Poisson regression analysis was conducted comparing NFR between these different patterns, adjusted for age (model 1). For the different patterns of cumulative exposure to physical work demands, only this model was investigated, as it is virtually impossible to decide which wave is most appropriate for the selection of confounders, as these might have varied during the period May 1998 to October 2008.

To longitudinally investigate the impact of the perceiving physical work demands as strenuous, Baecke work index quartiles measured at wave October 2008 and the different patterns of cumulative exposure to physical work demands on the dichotomous outcome NFR caseness, Cox regression analyses were performed investigating an unstratified model. Again, prevalent cases of elevated NFR were excluded for this analysis. Time to NFR caseness was modeled at wave October 2012 and a model adjusting for age was investigated (model 1). For the impact of perceiving physical work demands as strenous and Baecke work index quartiles also models 2,3 , and 4 , equal to the above mentioned models, were investigated.

The dichotomous outcome, chance of being out of employment, was also investigated by means of Cox regression analyses. The impact of perceiving physical work demands as strenuous, Baecke work index quartiles and patterns of cumulative exposure to physical work demands on this outcome were investigated. The risk of being out of employment was modeled at wave October 2012. Here, two models were investigated: a model adjusting for age (model 1) and a model additionally adjusting for baseline NFR scores (model 2). The latter model aimed to investigate the possible role of NFR in the pathway between physical work demands and the chance of being out of employment. Hazard ratios (HRs) and $95 \%$ confidence intervals (CIs) were reported.

Logistic regression analyses were performed to investigate cross-sectional associations between categories of perceiving physical work demands as strenuous and Baecke work index quartiles and retirement intentions and the ability to prolong working life at wave October 2012. Here, the same inclusion and exclusion criteria as mentioned above were used, although this resulted in a somewhat different study population as these criteria were based on the 2012 participants. For both retirement intentions items, the odds to agree with the statements on intentions to keep working until and beyond reaching the mandatory retirement age were investigated; a larger odds ratio (OR) implies a higher odds to agree with the statement. Two models were investigated: one model adjusting for age (model 1) and another model additionally adjusting for gender, living alone, educational level, and self-perceived health (model 2). For employees' ability to prolong working life, the odds to agree with the statement on whether employees considered themselves being physically able to perform their current job until reaching the mandatory retirement age was investigated: a larger OR implies a higher odds to agree with the statement. Finally, for the item whether less physical demands in the job would contribute to the prolongation of working life beyond the mandatory retirement age, the OR was investigated. Here, a larger OR implies higher odds that less physical demands, to at least some extent, would contribute to this. For both items, a model adjusting for age was investigated (model 1). ORs and 95\% CIs were reported.

To illustrate a possible healthy worker effect due to tertiary selection, Cox regression analysis was conducted to compare the risk of dropping out from the study population among the two categories of perceiving physical work demands as strenuous over a follow-up period of 32 months. Here, measurement May 1998 was the baseline: it was aimed to construct a similar study population as compared to the study baseline October 2008. Therefore, at measurement May 1998, all employees employed in the industry and health care sector aged 45 and older were included. Pregnant women and those involved in multiple jobs were excluded from the study. Next, time to drop out from the study population was modeled at follow-up waves T1 (September 1998), T2 (January 1999), T3 (May 1999), T4 (September 1999), T5 (January 2000), T6 (May 2000), T7 (September 2000), or T8 (January 2001) and the proportional hazard assumption was investigated and met. Additionally, to investigate whether a possible tertiary selection effect could also be illustrated among later follow-up waves, Cox regression analysis was conducted to compare the risk of dropping out from the study population among the Baecke work index quartiles during a follow-up period of 4 years. Here, the baseline population at October 2008 was investigated despite those who retired at wave October 2012 were no longer excluded. Next, the time to drop out from the study population was modeled at October 2012. SPSS 20.0 was used to analyze the data and in all analyses, a $P$ value of less than .05 was considered statistically significant.

\section{RESULTS}

\section{Descriptives}

The baseline characteristics of the study population are shown in Table 1. Statistically significant differences between the two categories of "perceiving physical work demands as strenuous" were observed with respect to personal characteristics (eg, gender, educational level), work characteristics (eg, decision latitude, supervisor social support), and Baecke index scores (eg, work index scores, sports and exercise index scores). The percentage of NFR cases was significantly higher in the "strenuous" category as compared to the "not strenuous" category, also after sector stratification. Among the Baecke work index quartiles, the lowest percentage of NFR cases was found in quartile 1 and the highest in quartile 4, also after sector stratification (specific data not shown).

\section{Need for Recovery}

In the longitudinal analyses (Table 2), unstratified results showed that NFR of employees who perceived their physical work demands as strenuous was statistically significantly higher in all four models as compared to employees who did not perceive their physical work demands as strenuous. After sector stratification, a similar pattern of findings in all four models was observed among the industry sector but not for health care employees. For the Baecke work index quartiles, NFR scores were statistically significantly lower in quartile 3 in overall models 2, 3, and 4 as compared to the 
TABLE 1. Overall and Sector-Stratified Description of Personal, Health, and Work Characteristics, Baecke Indexes, and NFR of the Study Population at Baseline Measurement October 2008 According to the Employees' Perception of Physically Demanding Work as Strenuous (Yes/No)

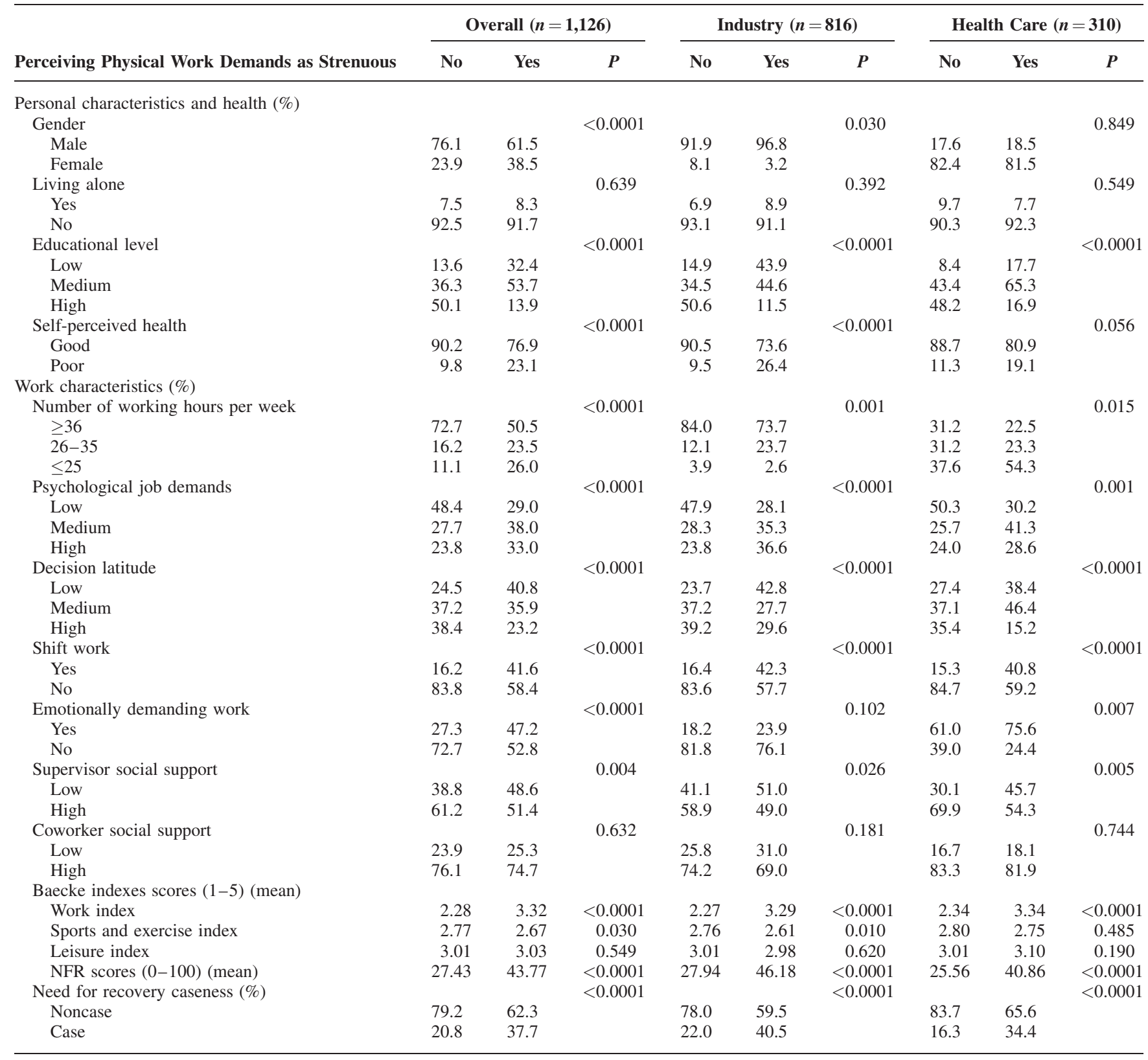

NFR scores in quartile 1. Similar results were observed among the industry sector. Among the health care sector, no statistically significant associations between the Baecke work index quartiles and NFR scores were observed in any of the models.

Furthermore, it was hypothesized that the combination of perceiving physical work demands as strenuous with the highest amount of physical work demands, as indicated by Baecke work index quartile 4, might result in stronger associations with NFR. Therefore, employees from Baecke work quartile 4 who also perceived their physical work demands as strenuous were compared to employees from Baecke work quartile 1 who did not perceive their physical work demands as strenuous. However, no statistically significant differences in NFR scores were observed in either the four models for the total study population, or after sector stratification (specific data not shown).

In Table 3, NFR scores of the four subgroups with different patterns of cumulative exposure to physical work demands throughout the work career are compared. As shown, NFR of the subgroup "continuous strainer" was significantly higher as compared to the reference group of "nonstrainers."

When longitudinally investigating the risk of becoming an elevated NFR case, results in Table 4 demonstrated that in model 1 , 


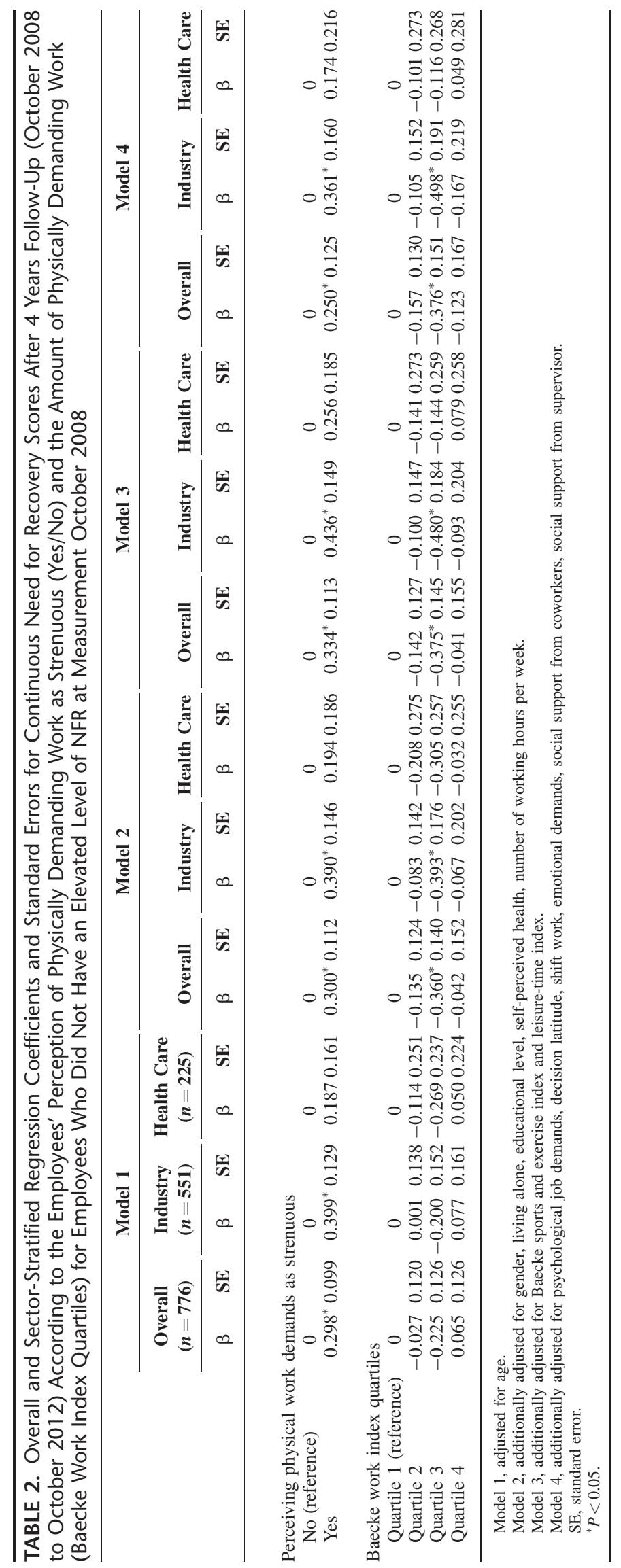


TABLE 3. Overall Regression Coefficients and Standard Errors for Continuous Need for Recovery Scores According to Patterns of Cumulative Exposure to Physical Work Demands (October 2008 to October 2012)

\begin{tabular}{lcc}
\hline & \multicolumn{2}{c}{ Model 1 (n=621) } \\
\cline { 2 - 3 } & $\beta$ & SE \\
\hline $\begin{array}{l}\text { Patterns of cumulative exposure } \\
\quad \text { to physical work demands }\end{array}$ & & \\
$\quad$ Nonstrainer (reference) & 0 & \\
Delayed strainer & 0.287 & 0.165 \\
Early strainer & -0.054 & 0.145 \\
Continuous strainer & $0.410^{*}$ & 0.185 \\
\hline Model 1, adjusted for age. & & \\
$\quad$ SE, standard error. & & \\
${ }^{*} P<0.05$. & & \\
\hline
\end{tabular}

any statistically significant higher risks for NFR caseness were not observed, neither for the categories of perceiving physical work demands as strenuous, or for the Baecke work index quartiles, or the patterns of cumulative exposure.

Employees who perceived their physical work demands as strenuous had a higher risk to become a case of elevated NFR in model 2 and model 3, the HRs being 1.77 (95\% CI $=1.01$ to 3.10$)$ and $1.95(95 \% \mathrm{CI}=1.11$ to 3.43$)$, respectively. In model 4 , this risk remained borderline significant: $\mathrm{HR}=1.83(95 \% \mathrm{CI}=1.00$ to 3.34). For the Baecke work index quartiles, statistically significant higher risks were not observed in any of the models (specific data not shown).

In conclusion, physical work demands were found to be associated with NFR in relation to the amount, perception, and patterns of cumulative exposure over time.

\section{Employment Status}

When investigating the chance of being out of employment (Table 4), employees who perceived their physical work demands as strenuous did not have a significantly higher risk to be out of employment as compared to those who did not perceive their physical work demands as strenuous $(\mathrm{HR}=1.54,95 \% \mathrm{CI}=0.99$ to 2.41), neither after adjusting for baseline NFR score.

The chance of being out of employment was significantly higher among employees in quartile 4 , as compared to employees in quartile $1(\mathrm{HR}=1.84,95 \% \mathrm{CI}=1.03$ to 3.29$)$, but not after correcting for baseline NFR score. Among the four subgroups with different patterns of cumulative exposure to physical work demands across the work career, the "continuous strainers" had a significantly higher risk of being out of employment as compared to the "nonstrainers" $(\mathrm{HR}=2.48,95 \% \mathrm{CI}=1.21$ to 5.07$)$. After correction for baseline NFR score, this risk remained borderline significant $(\mathrm{HR}=2.10,95 \% \mathrm{CI}=1.00$ to 4.38$)$.

\section{Retirement Intentions and Ability to Prolong Working Life}

When investigating the total sample at wave October 2012, $19.7 \%$ of the employees in quartile 1 reported that to some extent, high physical work demands contributed to the consideration to retire early, whereas among employees in quartile 4, this was reported by $87.0 \%$ of employees. Therefore, the impact of physical work demands should be further investigated, as this seems to be associated with the consideration of early retirement.

Table 5 demonstrates that in both model 1 and 2 of the two items assessing retirement intentions no statistically significant differences were observed when investigating the associations between physical work demands and retirement intentions, either for the categories of perceiving physical work demands as strenuous or for the Baecke work index quartiles. Results also showed that employees who perceived their physical work demands as strenuous had a significantly lower odds of agreeing with the statement that

TABLE 4. Overall HRs and $95 \%$ Cls for Need for Recovery Caseness and Chance of Being Out of Employment According to the Employees' Perception of Physically Demanding Work as Strenuous (No/Yes), the Amount of Physically Demanding Work (Baecke Work Index Quartiles), and Patterns of Cumulative Exposure to Physical Work Demands (October 2008 to October 2012)

\begin{tabular}{|c|c|c|c|c|c|c|}
\hline & \multirow{2}{*}{\multicolumn{2}{|c|}{$\begin{array}{c}\text { Need for Recovery } \\
\text { Caseness }\end{array}$}} & \multicolumn{4}{|c|}{ Chance of Being Out of Employment } \\
\hline & & & \multicolumn{2}{|c|}{ Model $1(n=1124)$} & \multicolumn{2}{|c|}{ Model 2} \\
\hline & HR & $95 \% \mathrm{CI}$ & HR & $95 \% \mathrm{CI}$ & HR & $95 \% \mathrm{CI}$ \\
\hline \multicolumn{7}{|c|}{ Perceiving physical work demands as strenuous } \\
\hline No (reference) & 1 & & 1 & & 1 & \\
\hline Yes & 1.55 & $0.94-2.54$ & 1.54 & $0.99-2.41$ & 1.46 & $0.92-2.31$ \\
\hline \multicolumn{7}{|l|}{ Baecke work index quartiles } \\
\hline Quartile 1 (reference) & 1 & & 1 & & 1 & \\
\hline Quartile 2 & 1.00 & $0.55-1.83$ & 1.10 & $0.57-2.12$ & 1.08 & $0.56-2.09$ \\
\hline Quartile 3 & 0.82 & $0.43-1.56$ & 0.72 & $0.35-1.49$ & 0.70 & $0.34-1.44$ \\
\hline Quartile 4 & 0.99 & $0.51-1.90$ & 1.84 & $1.03-3.29$ & 1.72 & $0.96-3.10$ \\
\hline \multicolumn{7}{|c|}{ Patterns of cumulative exposure to physical work demands } \\
\hline Nonstrainer (reference) & 1 & & 1 & & 1 & \\
\hline Delayed strainer & 1.96 & $0.91-4.21$ & 1.56 & $0.68-3.55$ & 1.46 & $0.64-3.33$ \\
\hline Early strainer & 0.69 & $0.29-1.64$ & 1.52 & $0.74-3.10$ & 1.54 & $0.75-3.15$ \\
\hline Continuous strainer & 1.28 & $0.46-3.58$ & 2.48 & $1.21-5.07$ & 2.10 & $1.00-4.38^{*}$ \\
\hline \multicolumn{7}{|c|}{$\begin{array}{l}\text { 95\% CI, 95\% confidence interval; HR, hazard ratio. } \\
\text { Model 1, adjusted for age. } \\
\text { Model 2, additionally adjusted for baseline NFR score. } \\
{ }^{*} \text { Borderline significance. }\end{array}$} \\
\hline
\end{tabular}




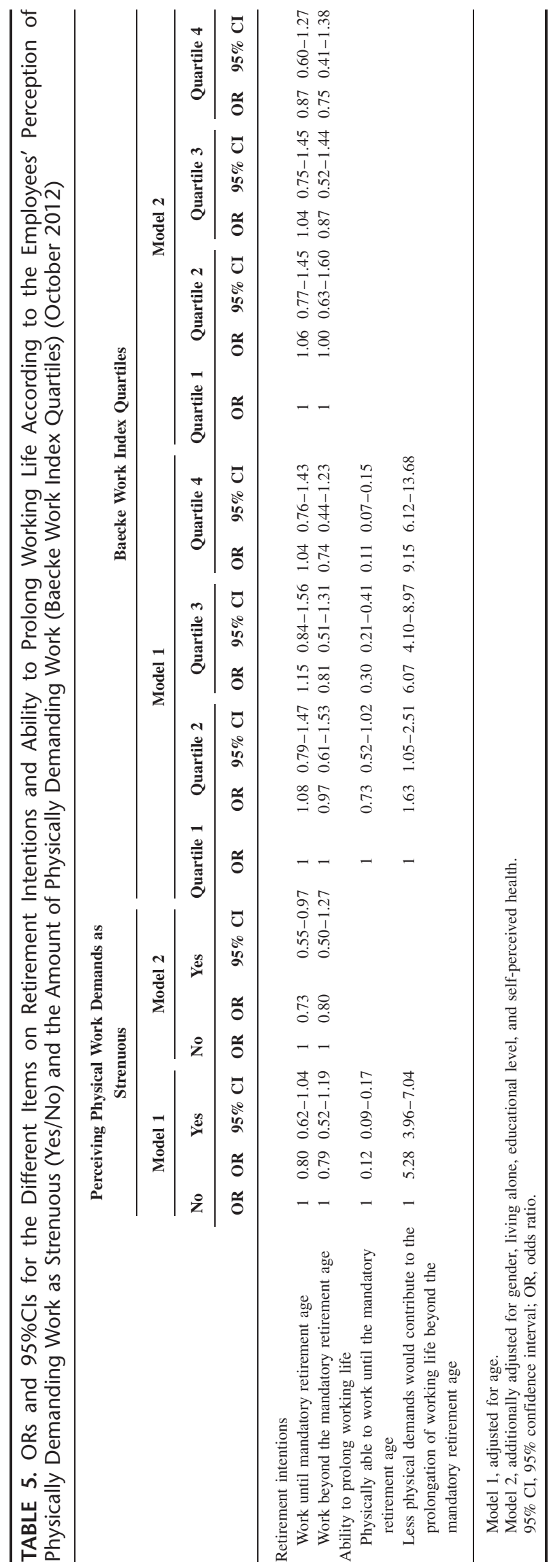

they were "physically able to perform their current job until reaching the mandatory retirement age" $(\mathrm{OR}=0.12,95 \%$ $\mathrm{CI}=0.09$ to 0.17 ). Also, employees in both quartiles 3 and 4 of the Baecke work index had a lower odds to agree with this statement as compared to employees in quartile 1 with $\mathrm{OR}=0.30$ $(95 \% \mathrm{CI}=0.21$ to 0.41$)$ and $\mathrm{OR}=0.11(95 \% \mathrm{CI}=0.07$ to 0.15$)$, respectively.

Employees who perceived their physical work demands as strenuous had significantly higher odds to agree with the statement that "less physical demands in the job would contribute to the prolongation of working life beyond the mandatory retirement age" $(\mathrm{OR}=5.28,95 \% \mathrm{CI}=3.96$ to 7.04$)$ as compared to employees who did not perceive their physical work demands as strenuous. For the Baecke work index quartiles, all quartiles had significant higher odds to agree with the statement as compared to employees in quartile 1: the ORs being $1.63(95 \% \mathrm{CI}=1.05$ to 2.51$), 6.07(95 \%$ $\mathrm{CI}=4.10$ to 8.97$)$, and $9.15(95 \% \mathrm{CI}=6.12$ to 13.68$)$ for quartiles 2 , 3 , and 4 , respectively.

\section{Healthy Worker Effect}

In Table 6, results investigating a tertiary healthy worker effect are presented for two different follow-up periods. Employees who perceived their physical work demands as strenuous had a significantly higher risk to drop out from the study population during the follow-up period May 1998 to January 2001 ( $\mathrm{HR}=1.39,95 \% \mathrm{CI}=1.21$ to 1.60$)$ as compared to employees who did not perceive their physical work demands as strenuous. When investigating this risk among the Baecke work index quartiles during the 4-year follow-up period October 2008 to October 2012, employees in quartile 4 (those with the highest physical work demands) had a significantly greater risk to drop out from the study population as compared to employees in quartile $1(\mathrm{HR}=1.44,95 \%$ $\mathrm{CI}=1.04$ to 1.99$)$.

\section{DISCUSSION}

\section{Main Findings}

The aim of this prospective study was to investigate whether different approaches of physical work demands were associated with NFR, being out of employment, retirement intentions, and the ability to prolong working life. Furthermore, a tertiary healthy worker effect was illustrated by investigating whether employees with higher physical work demands selectively drop out from the study population.

In the longitudinal analyses, perceiving physical work demands as strenuous was found to be associated with higher levels of NFR both in the total study population and the stratum industry sector, although not statistically significant in the health care sector. Also, those who perceived physical work demands as strenuous had a higher risk to become a case of elevated NFR. When investigating the Baecke work index quartiles, statistically significant negative associations between Baecke work index and NFR were observed only among employees in quartile 3. Possible explanations for these negative associations might be that the amount of physical work demands in quartile 3 might be a more optimal demand as compared to the amount in the reference group, as not only high physical work demands were associated with adverse outcomes, but also sedentary work was found to be a risk factor for adverse outcomes, ${ }^{41}$ which might be highly prevalent among employees in quartile 1 . Another explanation for these negative associations might be that these specific analyses were performed in a sample of employees who were not a NFR case at baseline, which might have resulted in a selected population, comprising employees who are currently able to cope adequately with physical work demands.

Differences in NFR levels were also observed when investigating different patterns of exposure to physical work demands. 
TABLE 6. Overall HRs and $95 \%$ Cls for the Risk of Study Dropout According to the Employees' Perception of Physically Demanding Work as Strenuous (Yes/No) (May 1998 to January 2001) and the Amount of Physically Demanding Work (Baecke Work Index Quartiles) (October 2008 to October 2012)

\begin{tabular}{lcc}
\hline & \multicolumn{2}{c}{$\begin{array}{c}\text { Chance of Dropout From the } \\
\text { Study Population }\end{array}$} \\
\cline { 2 - 3 } & HR & 95\% CI \\
\hline $\begin{array}{l}\text { Perceiving physical work } \\
\quad \text { demands as strenuous }(n=2326)\end{array}$ & & \\
$\quad$ No (reference) & 1 & \\
$\quad$ Yes & 1.39 & $1.21-1.60$ \\
Baecke work index quartiles $(n=1500)$ & & \\
$\quad$ Quartile 1 (reference) & 1 & $0.88-1.74$ \\
$\quad$ Quartile 2 & 1.23 & $0.92-1.78$ \\
$\quad$ Quartile 3 & 1.28 & $1.04-1.99$ \\
$\quad$ Quartile 4 & 1.44 & \\
\hline
\end{tabular}

95\% CI, 95\% confidence interval; HR, hazard ratio.

Although the findings were in the expected direction, NFR levels among delayed strainers did not statistically significantly differ from NFR levels of nonstrainers. A possible explanation for this finding might be that the perception of the physical demands changes: employees may start to perceive their physical work demands as more strenuous, while they are still able to cope well with these demands, therefore not resulting in significantly higher NFR levels as compared to nonstrainers. NFR levels of earlier strainers were also not significantly different from levels of nonstrainers. Possibly, secondary healthy worker effects might have taken place among the early strainers; as the physical capacity of employees declines, those no longer able to perform physically demanding work might have adjusted their work situation by reducing the amount of physical work demands by switching to a less strenuous job, or adjusting their job tasks, resulting in a NFR level, which does not (or no longer) differ from nonstrainers. Furthermore, employers might have introduced measures to spare employees, as a study ${ }^{42}$ demonstrated that employers regularly implement measures in which older employees are facilitated to perform less or lighter strenuous work. Higher NFR levels were demonstrated among continuous strainers as compared to nonstrainers. Possibly a cumulative exposure to perceiving physical work demands as strenuous might result in high levels of NFR. Another possible explanation could be that possibilities for job mobility or adaptation were low for the continuous strainers. Job mobility is often low in labor-intensive industries, ${ }^{43}$ which might explain why some employees were unable to change jobs or adjust their jobs tasks, leaving them employed in jobs that might result in high levels of NFR.

As high levels of NFR were associated with changes in labor participation in earlier studies, ${ }^{3,14,15}$ the risk of becoming unemployed was also investigated. In line with earlier studies ${ }^{44,45}$ physical work demands were found to be associated with a higher risk of being out of employment. After adjusting for NFR baseline scores, this risk was no longer found to be significant (or resulted in borderline significance). Therefore, this study demonstrated that high levels of NFR might be one of the important factors linking the pathway between high physical work demands and the risk of being out of employment.

Employees with higher physical work demands considered themselves to be less physically able to work until their retirement age and also perceived that less physical demands in the job would contribute to the prolongation of working life. However, no differences were observed when comparing the intentions to work until and beyond the mandatory retirement across the two categories of perceiving physical work demands as strenuous and the Baecke work index quartiles. A possible explanation for this finding might be that the impact of physical work demands was somewhat concealed, as a considerable number of other possible underlying reasons are also associated with retirement intentions. For example, a study ${ }^{46}$ concluded that the employees' financial opportunity to retire was the most important predictor of early retirement, and a positive attitude of the partner with respect to early retirement, and high social support of colleagues were also associated with the decision to retire early. Furthermore, the cross-sectional nature of these analyses could have contributed to this finding, and possibly a longitudinal time window could have resulted in a different outcome. It is also possible that the impact of physical work demands on retirement intentions had occurred earlier, whereas those employees with strong retirement intentions may have already left the labor force.

This study found that employees with physical work demands had a higher risk to drop out from the study population over the course of the cohort. It can be concluded therefore that the number of employees with physical jobs demands might be an underestimation of the true prevalence. Altogether, as selection processes seem to have taken place, the findings of the present study might be an underestimation of the true results.

\section{Methodological Considerations}

Several methodological aspects should be considered. A major strength of this study was that the large cohort allowed for longitudinal investigation of the impact of physical work demands on different outcome measures, while taking into account important confounders, and investigated the healthy worker effect explicitly.

Taking multiple confounders into account was justified, as in the descriptive analyses differences in personal, health, and work characteristics were observed between the two categories of perceiving physical work demands as strenuous or not. This implies that these jobs not only differ in physical demands but also in other work characteristics, such as psychological job demands and decision latitude. In the cross-sectional analyses, both mean NFR scores and the percentage of NFR cases were higher among employees who perceived physical work demands as strenuous as compared to employees who did not perceive their work as strenuous.

Also, the cohort allowed for a sector-specific approach, which is valuable as differences were observed among the two sectors in both personal and work characteristics, which are possibly associated with the outcomes. Since 2006, several measures have been undertaken in the Netherlands to discourage employees to retire early (eg, abolishment of tax advantages of early retirement and pre-pension schemes), which might have affected the retirement intentions of the study population. However, as such measures were often implemented on a sectoral level, again the sector-specific approach is valuable because the measures taken might be more comparable across employees employed within the same economic sector. In conclusion, this approach allows for the investigation of a rather homogenous population of employees with physical work demands as compared to employees without physical job demands within the same economic sector.

Another strength of this study was that various methods were used to assess physical work demands, which allowed for the investigation of different approaches of physical work demands. The amount of physical work demands was assessed with use of the Baecke work index, which comprised both more objective (ranking of energy expenditure of occupations) and subjective elements. Also, the perception of physical work demands was investigated, as well as different patterns of physical work demands, which could 
be well-defined as data was collected over a long time period. These distinctive methods are valuable, as results strongly differed among these different approaches of physical work demands. For example, perceiving physical work demands as strenuous was found to be associated with higher NFR levels, whereas different findings were observed when investigating the Baecke work index quartiles. Although this study assessed physical work demands comprehensively, a recommendation for future research would be to additionally examine the impact of specific types of physical work demands (eg, lifting, pulling), as these might be perceived differently in terms of load, and are possibly differently associated with outcomes. Therefore, a suggestion for future studies would be to investigate physical work demands more specifically, for example, on a jobspecific level. Although the four most prevalent and relevant patterns of physical work demands were investigated, not the entire variety of possible patterns was considered, as this study aimed to investigate only those patterns with the largest contrast in terms of perceiving physical work demands as strenuous over time.

On the basis of descriptive analyses, job mobility was not highly prevalent among the study population; however, it has not been investigated whether among the patterns of perception of physical work demands, the employees' actual perception of physical work demands has changed, or whether changes in perception were preceded by changes in jobs or job tasks.

As this study investigated a large scope of outcomes, different techniques of data analysis were required and different populations were investigated, which might hinder direct comparisons between the study findings. For example, as items on retirement intentions and the ability to prolong working life were first assessed in wave October 2012 of the MCS, a somewhat different study population was investigated for the cross-sectional analyses, although equal inclusion and exclusion criteria were applied. For conceptual reasons, employees who were retired at wave October 2012 were excluded from the analyses. As such, associations between physical work demands and NFR and risk of being out of employment have not been investigated among employees who were (close to) reaching retirement, as their situation might have biased the results. As all employees who retired during this 4-year period were excluded, this implies that also employees who were a few years away from reaching retirement were excluded. It remains unclear whether or not these employees already have a potentially different outlook on retirement, which might be associated with changes in the outcomes, and therefore might have possibly biased the results. As this approach might have been somewhat conservative, a suggestion for future studies would be to exclude only employees who are very close in time to reaching retirement, which was not possible in the present study due to practical limitations.

In line with earlier studies, ${ }^{29,30}$ the present study defined four subgroups comprising employees with different amounts of physical work demands based on the Baecke work index quartile cut-off scores of the study baseline population. The use of cut-off points that are based on the scores of the study population might be somewhat arbitrary or pragmatic, as these might vary across populations. However, to date, as no general cut-offs scores for the Baecke work index have been defined, the use of sample-specific quartiles was therefore considered to be an appropriate method to construct the subgroups with contrasting amounts of physical work demands. Although it was presumed that physical work demands would be highly prevalent in the study population, the variance in absolute Baecke work index scores was relatively small across the quartiles, which might explain why associations between the Baecke work quartiles and NFR were limited.

Furthermore, the choice for the subgroup comprising employees with the lowest amount of physical work demands (quartile 1) to be the reference group might be ambiguous. This subgroup might comprise employees who only or mainly perform sedentary work, whereas sedentary work also was found to be a risk factor for adverse health outcomes, ${ }^{41}$ which might result in other adverse outcomes investigated in this study, for example, early retirement intentions. ${ }^{20}$ Therefore, adverse outcomes might be observed among both employees performing only or mainly sedentary work as well as employees with the highest physical work demands, as both are associated with adverse outcomes, and therefore no differences in outcomes might be observed when comparing these two groups. An indication for this interpretation was observed in the present study, as only employees in Baecke work index quartile 3 had statistically significantly lower NFR scores as compared to employees in quartile 1 , possibly implying that employees with moderate physical work demands had less adverse outcomes as compared to employees with none or low physical work demands. A suggestion for future studies could be to compare employees with high physical work demands to a more contrasting reference group, for example, employees performing a moderate amount of physical work. In conclusion, both a limited contrast in terms of prevalence of physical work demands and the choice for a possible ambiguous reference group might explain why limited effects were observed when comparing the Baecke work index quartiles.

The present study focused on two economic sectors in which physical work demands were expected to be highly prevalent. Although multiple companies from the industry and the health care sector were included in the MCS, it remains uncertain whether these companies are a truly representative sample of the total economic sector. The vast majority of the companies investigated are situated in the Netherlands, therefore the findings of this study should be considered in the Dutch context. Physical work tasks such as heavy lifting and working in awkward postures are less prevalent in the Netherlands as compared to the European average. ${ }^{47}$ As a result, the prevalence of vigorous jobs is relative low in the MCS. Also, the retirement intentions of the study population might have been affected by national retirement policies and are therefore not readily comparable to retirement intentions of employees working in other countries. Moreover, since 2006 several measures have been undertaken in the Netherlands to discourage employees to retire early, which might have affected the retirement intentions of employees in this study. Although associations between physical work demands and retirement intentions were adjusted for multiple confounders, a suggestion for future studies would be to also consider other relevant confounders, such as employees' financial opportunity to retire.

Different manifestations of the healthy worker effect might have taken place. First, though not explicitly investigated, primary selection effects might have taken place in which employees never choose to perform a job with high physical demands. The secondary healthy worker effect might have been illustrated as several subgroups with high physical work demands showed to have a higher risk of being out of employment as compared to employees with lower physical work demands. Also, a tertiary selection effect was illustrated, as employees with physical work demands had a higher risk to drop out from the study population. Therefore, the findings in this study might have been an underestimation of the true results, since selection effects seem to be present in this study.

\section{Conclusion and Implications}

This study demonstrated that physical work demands were associated with adverse outcomes over time, such as higher levels of NFR among those who perceived their physical work demands as strenuous and the risk of being out of employment among those with continuous physical strain. The latter finding implies that also a cumulative effect of physical work demands on adverse outcomes was present in this study. Additionally, physical work demands had a cross-sectional association with a reduced ability to prolong working life, but were not found to be associated with retirement 
intentions. This may be due to the fact that the variance of physical work demands was somewhat low in this study.

As a tertiary healthy worker effect was present, the findings of this study might be an underestimation of the true results. As research on the healthy worker effect is limited, a suggestion for further studies would be to investigate whether primary and secondary selection processes also take place among employees with physical work demands. An important contribution of this study is that physical work demands were found to be associated with adverse outcomes over time. Therefore, an implication of this study is that tools and resources to adjust the amount of physical work demands might be useful preventive measures to achieve sustainable employment among older employees, which might contribute to the prolongation of working life until reaching the mandatory retirement age.

This study demonstrated that distinctive approaches to assess physical work demands resulted in different findings, and as such in different insights, as for example, the perception of physical work demands was found to be differently associated with NFR levels as compared to the amount of physical work demands assessed with the Baecke work index. Therefore, an important contribution of the present study is that the different methods to assess physical work demands should be carefully considered, since solely focusing on one approach does not provide full insight into the impact of physical work demands on outcomes. It would be even more optimal to use a combination of objective and subjective methods to assess physical work demands within a study, as such an approach would result in a more comprehensive overview of the impact of physical work demands on adverse outcomes.

\section{REFERENCES}

1. Statistics Netherlands. More than half of employees are 65 years or older at retirement. Available at http://www.cbs.nl/en-GB/menu/themas/arbeidsociale-zekerheid/publicaties/artikelen/archief/2015/more-than-half-ofemployees-are-65-years-or-older-at-retirement.htm. Accessed April 15, 2015.

2. Van Soest A, Vonkova H. How sensitive are retirement decisions to financial incentives? A stated preference analysis. J Appl Econ. 2014;29:246-264.

3. Oude Hengel KM, Blatter BM, Geuskens GA, Koppes LLJ, Bongers PM. Factors associated with the ability and willingness to continue working until the age of 65 in construction workers. Int Arch Occup Environ Health. 2012;85:783-790

4. Statistics Netherlands. More than one in three employees prepared to work until the age of 65 . Available at: http://www.cbs.nl/en-GB/menu/themas/ arbeid-sociale-zekerheid/publicaties/artikelen/archief/2009/2009-2966 wm.htm?Languageswitch=on. Accessed April 2, 2015

5. Lunde L-K, Koch M, Knardahl S, et al. Musculoskeletal health and work ability in physically demanding occupations: study protocol for a prospective field study on construction and health care workers. BMC Public Health 2014;14:1075.

6. Blekesaune M, Solem PE. Working conditions and early retirement: a prospective study of retirement behavior. Res Aging. 2005;27:3-29.

7. Rasmussen CD, Andersen LL, Clausen T, Strøyer T, Jørgensen MB, Holtermann A. Physical capacity and risk for long-term sickness absence: a prospective cohort study among 8664 female health care workers. $J$ Occup Env Med. 2015;57:526-530.

8. Van den Berg TIJ, Elders LAM, Burdorf A. Influence of health and work on early retirement. J Occup Env Med. 2015;57:184-187.

9. Loeppke RR, Schill AL, Chosewood LC, et al. Advancing workplace health protection and promotion for an aging workforce. J Occup Env Med. 2013;55:500-506.

10. Sluiter JK, de Croon EM, Meijman TF, Frings-Dresen MH. Need for recovery from work related fatigue and its role in the development and prediction of subjective health complaints. Occup Environ Med. 2003;60:i62-i70.

11. Van Veldhoven M, Broersen S. Measurement quality and validity of the 'need for recovery' scale. Occup Environ Med. 2003;60:i3-i9.

12. Hartig T, Staats H. Guest editors' introduction: restorative environments. $J$ Environ Psychol. 2003;23:103-107.

13. De Raeve L, Kant IJ, Jansen NWH, Vasse RM, van den Brandt PA. Changes in mental health as a predictor of changes in working time arrangements and occupational mobility: results from a prospective cohort study. J Psychosom Res. 2009;66:137-145.

14. De Croon EM, Sluiter JK, Frings-Dresen MH. Need for recovery after work predicts sickness absence: a 2-year prospective cohort study in truck drivers. J Psychosom Res. 2003;55:331-339.

15. Otten F, Arts K, Schuring M, Burdorf A. Het effect van werkbelasting op voortijdige arbeidsuittreding bij ouderen [The effect of workload on premature labour force exit]. Sociaaleconomische trends. Statistics Netherlands;. 2012;53-59.

16. Kiss P, de Meester M, Braeckman L. Differences between younger and older workers in the need for recovery after work. Int Arch Occup Environ Health. 2008;81:311-320.

17. Mohren DCL, Jansen NWH, Kant IJ. Need for recovery from work in relation to age: a prospective cohort study. Int Arch Occup Environ Health. 2010;83:553-561.

18. Jansen NWH, Kant IJ, van den Brandt PA. Need for recovery in the working population: description and associations with fatigue and psychological distress. Int J Behav Med. 2002;9:322-340.

19. Rook JW, Zijlstra FRH. The contribution of various types of activities to recovery. Eur J Work Organ Psy. 2006;15:218-240.

20. Von Bonsdorff ME, Huuhtanen P, Tuomi K, Seitsamo J, et al. Predictors of employees' early retirement intentions: an 11-year longitudinal study. Occ Med. 2010;60:94-100.

21. Hartvigsen J, Bakketeig LS, Leboeuf-Yde C, Engberg M, Lauritzen T. The association between physical workload and low back pain clouded by the "healthy worker" effect: population-based cross-sectional and 5-year prospective questionnaire study. Spine. 2002;26:1788-1793.

22. Neophytou AM, Picciotto S, Hart JE, Garshick E, Eisen EA, Laden F. A structural approach to address the healthy-worker survivor effect in occupational cohorts: an application in the trucking industry cohort. Occup Environ Med. 2014;71:442-447.

23. Shephard RJ. Limits to the measurement of habitual physical activity by questionnaires. Br J Sports Med. 2003;37:197-206.

24. Seidler A, Bolm-Audorff U, Heiskel H, et al. The role of cumulative physical work load in lumbar spine disease: risk factors for lumbar osteochondrosis and spondylosis associated with chronic complaints. Occup Environ Med. 2001;58:735-746.

25. Kant IJ, Bültmann U, Schröer KAP, Beurskens AJHM, van Amelsvoort LGPM, Swaen GMH. An epidemiological approach to study fatigue in the working population: the Maastricht Cohort Study. Occup Environ Med. 2003;60(suppl I):i32-i39.

26. Mohren DCL, Jansen NWH, van Amelsvoort LPGM, Kant IJ. An epidemiological approach of fatigue and work. In: Experiences From the Maastricht Cohort Study. Maastricht: Programma Epidemiologie van Arbeid en Gezondheid Maastricht University; 2007.

27. Baecke JA, Burema J, Frijters JE. A short questionnaire for the measurement of habitual physical activity in epidemiological studies. Am J Clin Nutr. 1982;36:936-942.

28. Ainsworth BE, Haskell WL, Herrmann SD, et al. 2011 Compendium of physical activities: a second update of codes and MET values. Med Sci Sports Exerc. 2011;43:1575-1581.

29. Evenson KR, Rosamond WD, Cai J, et al. Physical activity and ischemic stroke risk. The atherosclerosis risk in communities study. Stroke. 1999;30:1333-1339.

30. Mertens AJ, Sweeney C, Shahar E, Rosamond WD, Folsom AR. Physical activity and breast cancer incidence in middle-aged women: a prospective cohort study. Breast Cancer Res Treat. 2006;97:209-214.

31. Gründemann RWM, Smulders PWG, de Winter CR. Handleiding Vragenlijst Arbeid en gezondheid [Manual, Questionnaire on Work and Health]. Lisse: Swets \& Zeitlinger; 1993.

32. Broersen JPJ, Fortuin RJ, Dijkstra M, van Veldhoven M, Prins J. Monitor Arboconvenanten: Kengetallen en grenswaarden [Monitor working conditions agreements: indicators and cut-offs]. TBV. 2004;12: 100-104.

33. Van Dam K, van der Vorst JDM, van der Heijden BIJM. Employees' intentions to retire early: a case of planned behavior and anticipated work conditions. J Career Dev. 2009;35:265-289.

34. Koppes LLJ, de Vroome EMM, Mars GMJ, Janssen BJM, van Zwieten MHJ, van den Bossche SNJ. Nationale enquête arbeidsomstandigheden 2011. Methodologie en globale resultaten [National survey working conditions 2011. Methodology and global results]. Hoofddorp: Netherlands Organisation for Applied Scientific Research; 2011.

35. Institute for Policy Research and Advice. Vragenlijst duurzame inzetbaarheid en vitaliteit [Questionnaire Sustainable Employment and Vitality]; 2006 
36. Aaronson NK, Muller M, Cohen PD, et al. Translation, validation, and norming of the Dutch language version of the SF-36 Health Survey in community and chronic disease populations. J Clin Epidemiol. 1998;51: 1055-1068.

37. Dalstra JAA, Kunst AE, Geurts JJM, Frenken FJM, Mackenbach JP. Trends in socioeconomic health inequalities in the Netherlands, 1981-1999. J Epidemiol Commun Health. 2002;56:927-934.

38. De Raeve L, Jansen NWH, Kant IJ. Health effects of transitions in work schedule, workhours and overtime in a prospective cohort study. Scand $J$ Work Environ Health. 2007;33:105-113.

39. Houtman I. Reliability and validity of the Dutch version of the Karasek Job Content Questionnaire. Presented at NIOSH/APA conference on Stress, Work, and Health; September 14-16, 1995; Washington, DC.

40. Karasek R. The Job Content Questionnaire and User's Guide (version 1.1). Department of Industrial and Systems Engineering. Los Angeles: University of Southern California; 1985.

41. Mackey MG. Promoting healthy working life in an ageing and increasingly sedentary society. Phys Ther Rev. 2013;18:358-367.
42. Netherlands Organisation for Applied Scientific Research. Duurzame inzetbaarheid in perspectief [Sustainable employment in perspective]. Available at http://www.voion.nl/downloads/9e767880-0f11-49c9-b31e-7bbf671d2478. Accessed April 29, 2015.

43. Hachen DS. Industrial characteristics and job mobility rates. Am Sociol Rev. 1992;57:39-55

44. Lund T, Iversen L, Poulsen KB. Work environment factors, health, lifestyle and marital status as predictors of job change and early retirement in physically heavy occupations. Am J Ind Med. 2001;40:161-169.

45. Salonen P, Arola H, Nygård C-H, Huhtala H, Koivisto A-M. Factors associated with premature departure from working life among ageing food industry employees. Occ Med. 2003;53:65-68.

46. De Wind A, Geuskens GA, Ybema JF, et al. Health, job characteristics, skills, and social and financial factors in relation to early retirement-results from a longitudinal study in the Netherlands. Scand J Work Environ Health. 2014;40:186-194.

47. Netherlands Organisation for Applied Scientific Research. Monitoring Work \& Employment 2011. Available at http://www.voion.nl/downloads/ 9e767880-0f11-49c9-b31e-7bbf671d2478. Accessed April 29, 2015. 